\title{
Editorial: health technology assessment in Austria
}

\author{
Claudia Wild · Ingrid Zechmeister-Koss
}

Received: 6 November 2018 / Accepted: 26 November 2018

(C) Springer-Verlag GmbH Austria, ein Teil von Springer Nature 2018

Health technology assessment (HTA) is defined as a multidisciplinary process that summarises information about the medical, social, economic and ethical issues related to the use of a health technology in a systematic, transparent, unbiased and robust manner. Its aim is to inform the formulation of safe, effective, health policies that are patient-focused and seek to achieve best value (EUnetHTA definition: https:// www.eunethta.eu/). HTA has been used as decision support for health policy since the early 1980s in some Scandinavian and Anglo-Saxon countries, but arrived in Austria (and other social insurance-based countries) much later due to a high level of decentralised and regional structures for decision-making. The initiative for founding an HTA institute in Austria came from a research funding institution rather than from health policy, when, in 2006, the Ludwig Boltzmann Gesellschaft established a purely academic HTA institute (the Ludwig Boltzmann Institute for HTA; LBIHTA). Austria was already a latecomer in introducing HTA at that time, but-as such-could learn from the experiences of other countries. The major lesson to be learnt was that HTA can make the biggest impact if it is employed in connection with a concrete health policy information need before decisions are to be taken and with policy instruments (e.g., benefit catalogues) already in place rather than with general health system research. Within the last 13 years, the need for evidence-based support for sometimes difficult reimbursement and investment or even disinvestment decisions in health care has increased. Because of this need to support Austrian health pol-

C. Wild (凶)

Ludwig Boltzmann Institute for Health Technology

Assessment, Garnisongasse 7/20, 1090 Vienna, Austria

claudia.wild@hta.lbg.ac.at icy, the LBI-HTA will be transferred into another legal entity, the Austrian Institute for HTA (AIHTA), in 2020. This will be co-financed by the Ministry of Health, the Federation of Social Insurances and the nine regional health funds.

In 2008/2009, the Wiener Medizinische Wochenschrift invited the then-new LBI-HTA to write a series of five articles (WMW 158/159) on methodologies just a few years after its foundation. Now, ten years later, the LBI-HTA can look back and is reporting on major advancements in the utilisation of HTA in decisionmaking in Austria in a further series of four papers. The article by Grössmann et al. describes the use of HTA for early pre-coverage decisions on costly drugs in oncology and on new surgical interventions in hospitals. In contrast to those mostly single technology assessments, the article by Reinsperger et al. presents a methodological approach to assess complex public health interventions, including stakeholder involvement, in the formulation of recommendations. Health economic analyses play a rather limited role in Austrian HTA: The article by Zechmeister-Koss et al. analyses the reasons and challenges, and shows a way forward for incorporating economics more often into future HTAs. Since Austria is a small country which cannot conduct assessments on the full spectrum of health technologies, the LBI-HTA has been engaged in European HTA since the beginning and plays a strong role in coordinating collaborative assessments within EUnetHTA. The article by Erdös et al. describes the activities of the European network for HTA in detail. We hope that the articles will be of interest to the $W M W$ readership.

Conflict of interest C. Wild and I. Zechmeister-Koss declare that they have no competing interests. 